\title{
Spotlight on measles 2010: An ongoing measles outbreak in the district of Neamt, Romania, August - September 2010
}

\author{
A Stanescu (aurora.stanescu@insp.gov.ro) ${ }^{1,2}$, M Muscat ${ }^{2,3}$, A Romaniuc ${ }^{4}$, R Pipirigeanu ${ }^{5}$, E Lupulescu ${ }^{6}$, G Necula ${ }^{6}$, M Lazar $^{6}$, \\ G Molnar ${ }^{7}$, A Pistol $^{1}$ \\ 1. National Institute of Public Health, National Centre for Communicable Diseases Surveillance and Control, Bucharest, Romania \\ 2. These authors contributed equally to this work \\ 3. EUVAC.NET hub, Department of Epidemiology, Statens Serum Institut, Copenhagen, Denmark \\ 4. National Institute of Public Health, Regional Centre of Public Health - Iasi, Romania \\ 5. Public Health Authority of the district of Neamt, Romania \\ 6. National Institute of Research and Development for Microbiology and Immunology 'Cantacuzino' - National Reference \\ Laboratory for Measles and Rubella, Bucharest, Romania \\ 7. Ministry of Health, Bucharest, Romania
}

Citation style for this article:

Stanescu A, Muscat M, Romaniuc A, Pipirigeanu R, Lupulescu E, Necula G, Lazar M, Molnar G, Pistol A. Spotlight on measles 2010: An ongoing measles outbreak in the district of Neamt, Romania, August -September 2010. Euro Surveill. 2010;15(40):pii=19682. Available online: http://www.eurosurveillance.org/ViewArticle. aspx?Articleld $=19682$

Article published on 7 October 2010

We report an outbreak of measles that has been ongoing in the district of Neamt, Romania, since 22 August 2010. As of 21 September, 17 of 21 suspected cases have been laboratory-confirmed and there was one measles-related fatality.

\section{Introduction}

An outbreak of measles was detected in late August 2010 in the Romanian north-eastern district of Neamt with an estimated population of 566,940 (2009) (Figure 1). Earlier in the year, between 1 January and 3 August, 15 cases of measles had been notified from different parts of the country. These included two family clusters among members of the Roma ethnic minority. The first cluster involving five family members

\section{FIGURE 1}

Measles cases in the district of Neamt, Romania, AugustSeptember 2010
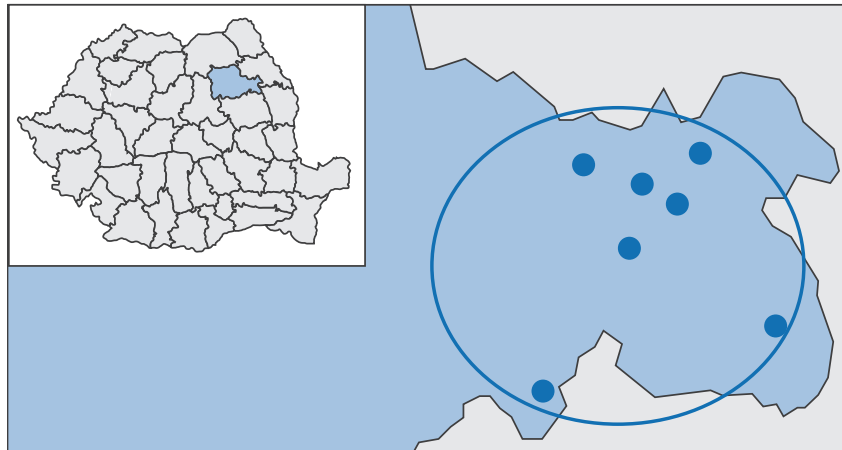

The blue spots indicate areas in Neamt affected where cases occurred. The blue circle indicates the containment area chosen for the vaccination campaign. occurred between late February and mid-March (weeks 7 and 11). The index case had a history of travel to France. The second cluster involved three cases in Neamt and occurred in mid-June (week 24). We report on the outbreak that emerged in Neamt by analysing preliminary data from late August to late September (weeks 33 to 38 ).

Measles is a statutorily notifiable disease since 1978 , obliging medical practitioners to immediately report suspected measles cases to the local Public Health Authorities. Notifications of measles cases are collected and analysed nationally at the National Centre for Communicable Diseases Surveillance and Control in Bucharest. National case-based notification was initiated in 1999 and the European Union (EU) case definition and case classification have been adopted since 2005 [1].

The measles vaccine was introduced in 1979 into the Romanian national immunisation programme for children 9-11 months of age. In 1994, the second measles vaccine dose was introduced for children six to seven years of age (first school grade). The combined measles-mumps-rubella (MMR) vaccine replaced the monovalent measles vaccine in 2004 and was recommended as a first dose for children at 12-15 months of age. The second MMR vaccine dose has been recommended since October 2005 for children at six to seven years of age. In the period form 2000 to 2008 , the national measles vaccination coverage for children aged 18-24 months with the first dose of measles-containing vaccine was estimated at 97-98\%. For children aged seven years, the measles vaccination coverage with the second dose was estimated at 96-98\% [2]. 


\section{Outbreak description}

Between 22 August and 21 September 2010, a total of 21 suspected cases were notified. In one case, the infection was fatal. The first measles cases of this outbreak were reported in two children and an infant. The close dates of onset of disease of these first cases suggest previous contact with an unreported case of measles.

Serum samples from all suspected cases were available for laboratory testing. Measles was confirmed in 17 of them (Figure 2), which corresponds to a crude incidence of three per 100,000 inhabitants in the district (95\% confidence interval (Cl): 1.9-4.9). Of the remaining four cases, three cases had a negative test result and were discarded and in one case the result is still pending.

Laboratory confirmation was performed by detecting measles IgM antibodies in serum samples. RT-PCR to detect measles virus nucleic acid was also used to confirm the first five cases. The National Reference Laboratory for Measles and Rubella 'Cantacuzino' identified measles virus genotype $\mathrm{D}_{4}$ in clinical specimens from these five cases.

The outbreak investigators reported that the laboratory-confirmed cases involved both the general population $(n=11)$ and members of the Roma ethnic community $(n=6)$. The median age was 11 months (range: four months to nine years). Ten of the 17 cases were infants (under the age of one year), six were one to four yearsold and one was in the age group from five to nine years. The status of measles vaccination was known in all notified cases. Fifteen cases were unvaccinated (Table). These included 10 infants who were not eligible for vaccination because of their age and five cases who were eligible but for whom the indicated reason for non-vaccination was contraindications including underweight, hydrocephalus and Down syndrome. The remaining two cases had been vaccinated with one dose of MMR.

The death was reported in a seven month-old, unvaccinated infant who was admitted to a paediatric ward with gastrointestinal symptoms, anaemia and pharyngitis. The infant later developed a rash and acute pneumonia

\section{FIGURE 2}

Number of measles cases by day of onset of rash, Neamt district, Romania, August-September 2010 ( $n=17)$

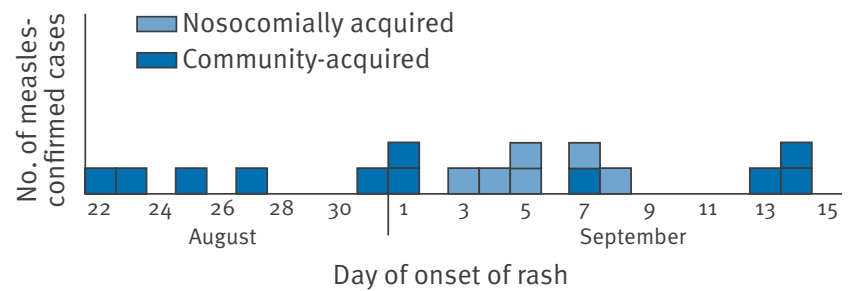

which was the ultimate cause of death. Of the 17 notified cases, 14 were hospitalised as in-patients in a paediatric ward. Six of those were probably infected with measles through nosocomial transmission on the ward.

\section{Control measures}

Several control measures have been implemented by local health authorities. A supplementary MMR vaccination campaign was started on 6 September in the defined containment area including all affected communities and neighbourhoods in Neamt (Figure 1). It targeted all children from seven months to seven years of age who did not have documented evidence of vaccination. The MMR vaccine was supplied by the Ministry of Health and offered free of charge through the routine immunisation services (family doctors) and special outreach teams in the community. Of 1,345 eligible individuals, 956 (71\%) have been vaccinated by 19 September 2010. In addition, existing MMR vaccination campaigns were reinforced in the border areas of four neighbouring districts close to the affected areas in Neamt.

Moreover, active case finding by general practitioners has been instigated in the areas where cases were living, as well as tracing contacts of cases in hospitals and in the community. All children with fever and rash were referred to the infectious disease ward and were investigated. MMR vaccination was given to all contacts between seven months and seven years of age who did not have documented evidence of vaccination. To date, 29 close contacts of the hospitalised patients were identified, nine of whom acquired measles (secondary attack rate: $31 \%$ ). Additional activities to increase awareness of the ongoing outbreak included sending medical bulletins with information to all physicians in the district and all public health authorities in the country.

\section{Discussion}

The source of this outbreak has not yet been identified. The earlier occurrence of measles in the same district in mid-June 2010, suggests that transmission may have continued unnoticed in the meantime. The local health

\section{TABLE}

Number of measles cases by age group and vaccination status, Neamt district, Romania, August-September 2010 $(\mathrm{n}=17)$

\begin{tabular}{|l|c|l|}
\hline Age group & $\begin{array}{c}\text { No. of } \\
\text { measles } \\
\text { cases }\end{array}$ & Vaccination status \\
\hline <1 year & 10 & Not eligible for vaccination \\
\hline 1-4 years & 6 & $\begin{array}{l}\text { 1 had received one MMR dose, } \\
\text { 5 had contraindications for vaccination }\end{array}$ \\
\hline 5-9 years & 1 & 1 had received one MMR dose \\
\hline Total & 17 & \\
\hline
\end{tabular}

MMR: measles, mumps, rubella vaccine. 
authorities may not have been notified or the cases may not have sought medical attention. Nevertheless, any link between the earlier cluster and this outbreak remains speculative.

Despite the high national vaccination coverage with MMR vaccine, this outbreak highlights the presence of pockets of individuals vulnerable to measles, in the general population and among members of the Roma community. The vulnerability of Roma communities to acquire measles is well documented, most recently with the outbreak that occurred in Bulgaria [3]. In areas and communities where vaccination coverage remains suboptimal, cohorts of susceptible individuals accumulate and represent a potential for outbreaks to occur. The current ongoing outbreak involves a large proportion of infants too young to be vaccinated according to the national childhood vaccination programme, which is indicative of widely circulating measles virus. A similar situation had been observed earlier in Romania in 2006 [4].

The five children with measles who were not vaccinated due to perceived contraindications may have been prevented. All of these children could have been vaccinated unless they also had a serious allergy to any of the ingredients of the MMR vaccine, an acute severe illness or severe immunodeficiency. Inadequate knowledge of the contraindications for MMR vaccination by general practitioners is a recognised problem that needs to be addressed.

In 2008 and 2009 the measles situation in Romania had improved dramatically compared with previous years, with reported incidences of less than 0.1 per 100,000 inhabitants $[5,6]$. However, the emergence of this outbreak highlights the need for urgent preventive and control measures to be taken once again. For the goal of measles elimination to be reached, awareness of the disease and a commitment by public health authorities in Romania are essential to strengthen vaccination programmes. The World Health Organization's strategic plan for the elimination of measles from the European region stipulates that vaccination programmes should achieve and sustain a minimum of $95 \%$ coverage with two doses of vaccine and should target susceptible individuals in the general population [7] as well as in vulnerable groups. Moreover, constant vigilance is needed to ensure that suspected measles cases are promptly investigated to identify outbreaks and instigate the control measures to curtail them.

\section{References}

1. European Commission. Commission Decision of 19 March 2002 laying down case definitions for reporting communicable diseases to the Community network under Decision No 2119/98/EC of the European Parliament and of the Council (2002/253/EC), Official Journal of the European Union. Luxembourg: Publications Office of the European Union. 3 Apr 2002. Available from: http://eur-lex.europa.eu/LexUriServ/ LexUriServ.do?uri=0J:L:2002:086:0044:0062:EN:PDF
2. World Health Organization (WHO). Immunization coverage. WHO/UNICEF estimates of na-tional immunization coverage. Geneva: WHO. Accessed 29 Sep 2010. Available from: http://www.who.int/immunization_monitoring/routine/ immunization_coverage/en/index4.html

3. Marinova L, Muscat M, Mihneva Z, Kojouharova M. An update on an ongoing measles outbreak in Bulgaria, AprilNovember 2009. Euro Surveill. 2009;14(50):pii=19442. Available from: http://www.eurosurveillance.org/ViewArticle. aspx?Articleld $=19442$

4. Muscat M, Bang H, Wohlfahrt J, Glismann S, Mølbak K, EUVAC. NET group. Measles in Europe: an epidemiological assessment. Lancet. 2009;373(9661):383-9.

5. EUVAC.NET. Measles surveillance annual report 2008. EUVAC. NET. 12 Nov 2009. Available from: http://www.euvac.net/ graphics/euvac/pdf/annual_2008.pdf

6. EUVAC.NET. Measles surveillance annual report 2009. EUVAC. NET. 25 May 2010. Available from: http://www.euvac.net/ graphics/euvac/pdf/annual_2009.pdf

7. World Health Organization Europe (WHO). Eliminating measles and rubella and preventing congenital rubella infection. WHO European Region strategic plan 2005-2010. Copenhagen: WHO Regional Office for Europe. 2005. Available from: http://www. euro.who.int/_data/assets/pdf_file/0008/79028/E87772.pdf 